\title{
Occurrence of infections in schoolchildren subsequent to supplementation with vitamin D-calcium or zinc: a randomized, double-blind, placebo-controlled trial
}

\author{
Rubina Mandlik ${ }^{1,2}$, Zulf Mughal ${ }^{3,4}$, Anuradha Khadilkar ${ }^{1,25}$, Shashi Chiplonkar ${ }^{1}$, Veena Ekbote', Neha Kajale', Vivek Patwardhan', \\ Raja Padidela ${ }^{3,4}$ and Vaman Khadilkar ${ }^{1}$ \\ 'Hirabai Cowasji Jehangir Medical Research Institute, Jehangir Hospital, 32, Sassoon Road, Pune - 411001, Maharashtra, India \\ ${ }^{2}$ Interdisciplinary School of Health Sciences, Savitribai Phule Pune University, Ganeshkind Road, Pune - 411007, Maharashtra, India \\ ${ }^{3}$ Department of Pediatric Endocrinology \& Metabolic Bone Diseases, Royal Manchester Children's Hospital, Oxford Road, Manchester M13 9WL, UK. \\ ${ }^{4}$ Faculty of Biology, Medicine and Health, University of Manchester, Oxford Road, Manchester M13 9PL, UK.
}

BACKGROUND/OBJECTIVES: Vitamin D and zinc are recognized for their roles in immune-modulation, and their deficiencies are suggested to be important risk factors for childhood infections. This study, therefore, undertook to assess the occurrence of infections in rural Indian schoolchildren, subsequent to daily supplementation with vitamin D-calcium or zinc for 6 months. SUBJECTS/METHODS: This was a randomized, double-blind, placebo-controlled trial in apparently healthy 6-12 year-old rural Indian children, recruited to 3 study arms: vitamin D arm (1,000 IU D3 - 500 mg calcium, $n=135)$, zinc arm (10 mg, $n=150)$ and placebo arm $(n=150)$. The infection status was assessed using a validated questionnaire, and the biochemical parameters of serum $25(\mathrm{OH}) \mathrm{D}$ and serum zinc were measured by ELISA and colorimetry, respectively. The primary outcome variable was occurrence of infections (upper respiratory and total infections).

RESULTS: Serum 25(OH)D concentration in the vitamin D arm improved significantly by $34 \%$, from $59.7 \pm 10.9 \mathrm{nmol} / \mathrm{L}$ to 80 $\pm 23.3 \mathrm{nmol} / \mathrm{L}(P<0.0001)$, but no improvement was observed for serum zinc concentration. While there was significant increase in the percentage of children reporting no or mild upper respiratory tract infections (URTI) and total infections (TI) in all three groups, improvements in the supplemented groups were similar to the placebo group. However, the vitamin D arm reported lower URTI and TI status in the vitamin D sufficient versus insufficient children. Also, URTI and TI status were found to be significantly $(P<0.0001)$ lower in children with improved $25(\mathrm{OH}) \mathrm{D}$ versus unchanged $25(\mathrm{OH}) \mathrm{D}$.

CONCLUSIONS: Vitamin D-calcium supplementation helped to improve the vitamin D status but exerts no effect on the occurrence of infections when compared to the placebo group. Improvement in the serum 25(OH)D concentrations and attainment of vitamin D sufficiency may exert a beneficial effect on the infection status and needs to be investigated further. To evaluate the efficacy of zinc supplementation, higher dosages need to be administered in future studies.

Nutrition Research and Practice 2020;14(2):117-126; https://doi.org/10.4162/nrp.2020.14.2.117; pISSN 1976-1457 elSSN 2005-6168

Keywords: Cholecalciferol, calcium carbonate, India, respiratory tract infections, zinc sulfate

\section{INTRODUCTION}

The high prevalence of malnutrition in India is alarming, as is evident from the recent National Family Health Survey (NFHS-4 2015-2016) report, which pegs prevalence of stunting at $41.2 \%$ and underweight at $38.2 \%$ in rural India [1]. The cyclic relationship between malnutrition and infections is well-known; infections worsen the nutritional status and, conversely, poor nutritional status results in increased susceptibility to infections, thereby leading to deteriorating health of the child [2]. Micronutrient malnutrition especially increases susceptibility to infections, since micronutrients play an important role in various mechanisms of the immune system, such as barrier integrity, production of immune cells, etc. [3].

Currently in the limelight, vitamin D is known to play a key role as an immunomodulator. Activation of toll-like receptors on monocytes and macrophages by foreign antigens results in increased expression of the CYP27B1 and vitamin D receptor (VDR) genes, with subsequent increase in the synthesis of both 1,25-dihydroxyvitamin D and VDR. The 1,25-dihydroxyvitamin $\mathrm{D}$ binds with VDR and induces synthesis of the antimicrobial peptides, cathelicidin (LL-37) and defensin, which are responsible

\footnotetext{
Rubina Mandlik was funded by a Fellowship Grant from the University Grants Commission, Government of India. Eris Lifesciences Ltd. Ahmedabad supplied the vitamin D-calcium supplements.

${ }^{\S}$ Corresponding Author: Anuradha Khadilkar, Tel. 91-20-26141340, Fax. 91-20-26141340, Email. anuradhavkhadilkar@gmail.com

Received: May 20, 2019, Revised: June 13, 2019, Accepted: August 13, 2019

This is an Open Access article distributed under the terms of the Creative Commons Attribution Non-Commercial License (http://creativecommons.org/licenses/by-nc/3.0/) which permits unrestricted non-commercial use, distribution, and reproduction in any medium, provided the original work is properly cited.
} 
for antimicrobial activities [4].

Maintaining the serum $25(\mathrm{OH}) \mathrm{D}$ levels consistently $\geq 75$ $\mathrm{nmol} / \mathrm{L}$ is suggested to be conducive to eliciting an appropriate immune response [5]. However, in spite of India being a tropical country with abundant sunshine throughout the year, a prevalence of up to $70-90 \%$ vitamin $D$ deficiency (serum $25(\mathrm{OH}) \mathrm{D}<50$ $\mathrm{nmol} / \mathrm{L}$ ) has been reported among Indians [6-8]. The reasons for vitamin D deficiency among Indians are multifaceted, and are associated with avoidance of sunshine (due to urbanization, cultural or religious reasons), consumption of calcium-deficient and phytate-rich, predominantly vegetarian diets, and genetic reasons (eg., up-regulation of CYP24A1 gene, resulting in increased degradation of $25(\mathrm{OH}) \mathrm{D}$ ) [6]. Calcium intake is an important factor to help overcome vitamin D deficiency; poor calcium intake is demonstrated to cause rapid degradation of serum $25(\mathrm{OH}) \mathrm{D}$ by inducing secondary hyperparathyroidism $[9,10]$. Diets of Indian children are found to be severely lacking in calcium, meeting only about $30 \%$ of the recommended dietary allowances (RDA) [11]. Hence, while calcium may not be directly involved in immune regulation, adequate calcium intakes are required to maintain the $25(\mathrm{OH}) \mathrm{D}$ concentration in the optimal range to facilitate maintenance of the immune regulating benefits [12].

Zinc is an essential micronutrient which plays a vital role in the functioning of the immune system, and zinc deficiency is characterized by depressed immune function. High prevalence of zinc deficiency has been reported among children under 5 years [13] and adolescent girls in India [14].

While there are reports from India on infections among 6-12 year old children and strategies to reduce them, most are focused on the urban population $[15,16]$. Trials aimed at reducing infections in this age group in rural India are scant, in spite of knowledge of prevalence of infections and malnutrition among them $[17,18]$.

Studies determining the effect of vitamin D supplementation on incidence of infections in children have yielded varied results. Quarterly supplementation with $100,000 \mathrm{IU}$ oral vitamin D for 18 months had no impact on reducing the incidence of either pneumonia [19] or diarrheal illness [20] in 1 to 11 month old infants in Kabul. Contrarily, another report indicated that supplementation with 1,200 IU cholecalciferol/day for 4 months, in children aged 6 to 15 years in Japan, reduces the incidence of wintertime influenza A [21].

To date, there is no consensus on the dose and frequency of vitamin $D$ supplementation required to induce an immune response [22]. Due to lack of conclusive evidence, it is important to study the effect of vitamin D supplementation on the occurrence of childhood infections in a population having a high prevalence of infections.

Trials from Turkey suggest that zinc supplementation contributes to reduction in severity, but not the duration, of common colds in 5 year old children [23]; another study reports the reduction of morbidity due to diarrhea in rural West African children aged 6 to 31 months [24]. Other trials, however, failed to demonstrate any benefits of zinc supplementation on the incidence of diarrhea or respiratory tract infections [25]. However, we found no intervention trial aimed at assessing the effect of zinc supplementation on infections in children aged 6-12 years in India.
Summarizing the literature available, we found that there is a high prevalence of infections among schoolchildren aged 6-12 years in rural India. Furthermore, several reports indicate both vitamin $\mathrm{D}$ and zinc deficiency among Indian children, with very few studies on interventions using vitamin $D$ or zinc supplements to reduce infections among children aged 6-12 years in rural areas. Therefore, we planned this randomized, double-blind, placebo-controlled trial with the primary objective of assessing the effect of supplementation with vitamin D3 (cholecalciferol) along with calcium, or supplementation with zinc, on the occurrence of infections in rural Indian schoolchildren. Our hypothesis is that there would be significant reduction in the occurrence of infections among the participants in both the vitamin $D$ as well as the zinc arms of the trial, as compared to participants in the placebo arm.

\section{SUBJECTS AND METHODS}

\section{Trial design and participants}

This randomized, double-blind, placebo-controlled trial was conducted in a Public Elementary School (Grade 1 to 4) located in a rural region $65 \mathrm{kms}$ east from Pune city $\left(18^{\circ} \mathrm{N}\right)$, Western India. Selection of the school was after surveying rural areas around Pune city to assess site accessibility, subject availability and cooperation of school authorities. We connected with the local governing authority to obtain a list of schools in the area, and 10 schools satisfying the inclusion criteria were short-listed and approached for consent. The final school was randomly selected from the 8 schools which consented for the trial to be executed on their premises.

Inclusion criteria of this study were children between the ages of 6-12 years who were not consuming any supplements or preparations containing vitamin D or calcium or zinc. Our exclusion criteria were children with congenital abnormalities, chronic medical conditions, and conditions which could affect the vitamin $D$ and calcium metabolism.

Totally, 544 children meeting the age criteria were enrolled from the selected school. All parents were approached for consent. Parents of 474 children provided written informed consents, and written informed assents were obtained from the children. Children whose parents had consented underwent a general medical examination by a pediatrician to rule out any medical conditions; 30 children were excluded due to pre-existing conditions including asthma, kidney stones, liver disease, growth hormone deficiency, thalassemia, and suspected neurodevelopmental delay. During blood collection, 9 children were absent. Finally, 435 children were enrolled in this trial. Allocations of children to the three trial arms were as follows: 135 to the vitamin $D$ arm, 150 to the zinc arm, and 150 to the placebo arm (Fig. 1).

Approval for the trial was obtained from the institutional ethics committee (Ethics Committee Jehangir Clinical Development Centre Pvt. Ltd.). The trial was registered with the Clinical Trials Registry-India (CTRI/2014/08/004854).

\section{Study period}

The trial was conducted from July 2014 to February 2015. The monsoon season in Pune lasts from July to September every 


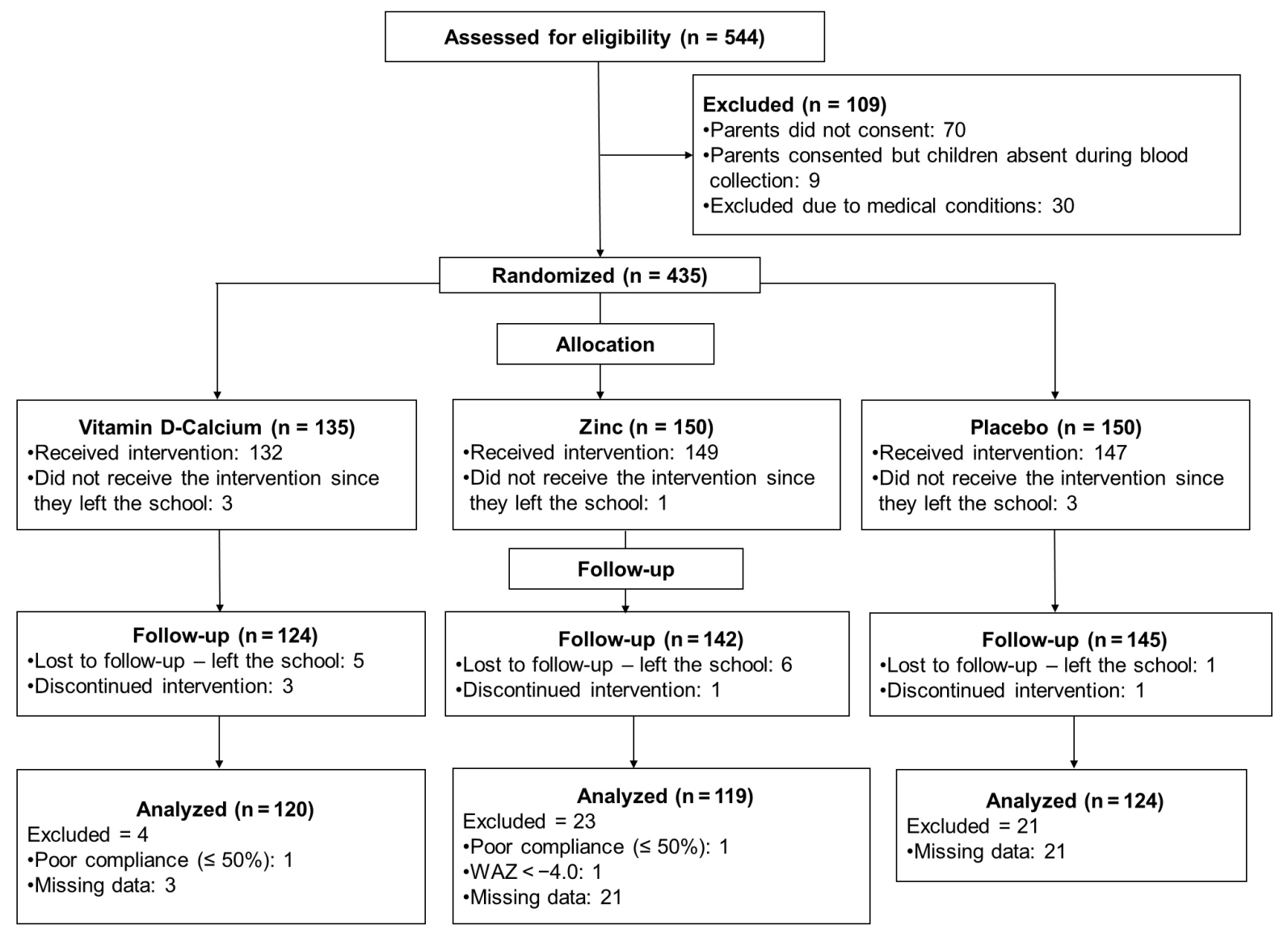

Fig. 1. CONSORT Diagram for participant flow

year. Pune, however, experiences adequate sunshine throughout the year, with average sunshine hours of $10.7,7.5$ and 9.4 hours during summer, monsoon and winter, respectively [26].

\section{Supplementation}

a. Vitamin D Supplementation: A vitamin D-calcium supplement containing 1,000 IU of cholecalciferol (vitamin D3) and $500 \mathrm{mg}$ of calcium as calcium carbonate was administered to the participants randomized to the vitamin $D$ arm. The above supplement composition was decided, since $600-1,000 \mathrm{IU}$ of vitamin D/day is the suggested daily intake for children aged 6-12 years who are at risk of vitamin D deficiency [27]. Additionally, in order to impart extraskeletal benefits by maintaining serum $25(\mathrm{OH}) \mathrm{D}$ consistently above $75 \mathrm{nmol} / \mathrm{L}$, a vitamin $\mathrm{D}$ intake of at least 1,000 IU/day has been suggested [27].

Furthermore, considering that diets of Indian children are deficient in calcium [11], which further exacerbates vitamin $\mathrm{D}$ deficiency [9], and the RDA for Indian children aged 6-12 years is $600-800 \mathrm{mg} /$ day [28], we provided a vitamin D supplement containing $500 \mathrm{mg}$ of calcium.

b. Zinc Supplementation: A supplement containing zinc sulfate providing $10 \mathrm{mg}$ of zinc was administered to participants in the zinc arm. The RDA of zinc for Indian children aged 6-12 years is 7-9 mg of zinc per day. Since additional recommendations regarding dose, duration and frequency of supplementation are not available, we decided to provide a supplement meeting the RDA requirement for zinc.

c. Placebo: The children in the placebo group were administered a tablet containing $10 \mathrm{mg}$ fructose.

\section{Blinding and randomization}

The vitamin D-calcium supplement was supplied by Eris Lifesciences Ltd., Ahmedabad, India. The zinc and placebo tablets were manufactured by SDS Nutraceuticals, Karad, India, to appear identical to the vitamin D-calcium tablet. The supplements and placebo were thus, similar looking white, oval-shaped tablets, and each weighing 1,500 mg. These were packed in high-density polyethylene plastic jars and labelled A, B and C. Coding of the supplements was performed by the supplier, and the codes were revealed only after completion of the trial. The trial staff as well as the participants were unaware of the intervention being administered, thereby achieving double blinding.

The cluster randomization method was used to randomly allocate the 435 participants to the three trial arms: vitamin $D$, zinc and placebo. Each class or grade in the school had 3 divisions, $A, B$ and $C$, which were categorized as the designated clusters. Children in the A divisions of all 4 classes were 
administered supplement from the bottles labelled $A$, those in $B$ divisions were administered supplement from the bottles labelled $B$, and those in $C$ divisions were administered supplement from the bottles labelled $C$.

\section{Compliance}

The supplementation process was rigorously monitored. Trained social workers administered the supplement/placebo to the participants in the classrooms during the first period, daily for 6 months. Records of supplement intake were maintained in a register, immediately after consumption. Every Saturday, a supplement packet was handed over to the child, with instructions to consume the same on Sunday. Caregivers were also reminded during each home-visit to ensure their child consumed the supplement. Furthermore, on the Monday that followed, it was enquired if the Sunday supplement had been consumed, and this was duly noted in the register.

The compliance percentage was computed as a percent of the number of days the participant consumed the supplement from the total number of days that the supplement was administered.

\section{Demographic and sunlight exposure data}

Demographic data were collected by administering a questionnaire and interviewing the primary caregiver of the participant. Data regarding parent's education and family income were also collected and used to assess the socio-economic status of the family by applying Kuppuswamy's method [29].

Sunlight exposure data relating to time of sunlight exposure, duration of exposure, use of cap or sunscreens, length of school uniform, and mode of transport to and from school, were recorded using a validated questionnaire administered to the participant in the presence of the primary caregiver [30].

\section{Living conditions and personal hygiene data}

To assess the living conditions and personal hygiene habits of the participants, the primary caregivers were interviewed in the presence of the participants using a validated questionnaire. Primary caregivers were asked about the type of house they lived in, waste disposal habits and water purification methods [31,32]. Participants were asked about their personal hygiene habits - how often they brushed their teeth and whether they washed their hands before meals and after visiting washrooms [31,32]. Data variables in the living conditions as well as personal hygiene data were scored as 0 for poor condition or habit, 5 for moderate, and 10 for appropriate condition or good habit. These were summarized, and percentages were calculated based on the best score attainable. The living condition percentage scores were coded as follows: $<50 \%$ poor living condition, $50-$ $60 \%$ fair, $61-80 \%$ good, and $>80 \%$ very good living conditions. Personal hygiene percentage scores were coded as follows: < $70 \%$ poor personal hygiene, $71-80 \%$ fair, $81-90 \%$ good, and $>90 \%$ very good personal hygiene [31,32].

\section{Anthropometric measurements}

Using a portable stadiometer (Seca 213 Portable Stadiometer, Germany), standing height was measured to the nearest $0.1 \mathrm{~cm}$. Body weight was measured using the Tanita Body Composition
Analyzer (Model BC-420MA). Body mass index (BMl, expressed as $\mathrm{kg} / \mathrm{m}^{2}$ ) was calculated using the formula: weight in $\mathrm{kg}$ divided by height in meters squared. Ethnic-specific growth references were used to compute height-for-age (HAZ), weight-for-age (WAZ), and BMI-for-age (BAZ) z-scores [33].

\section{Dietary history}

Trained nutritionists recorded dietary history using the 24-hour dietary recall method administered over 3 non-consecutive days, including Sunday or a holiday. For accurate estimation of food intake, participants and their primary caregivers were interviewed jointly. Nutrient intakes were estimated using the C-Diet software [34], which is based on the nutritive values of raw foods [35] and cooked foods [36]. The percentage of each nutrient consumed was calculated as per the RDA for Indian children [28].

\section{Biochemical estimations}

Blood collection was performed at two time points: baseline (before the intervention was started, July 2014), and endline (on completion of the supplementation period, March 2015). Venous blood samples were collected between 7 and 9 a.m. by trained phlebotomists, using plain BD Vacutainer blood collection tubes. The participants were instructed to come fasting for the blood collection. Serum separation was achieved within 4 hours of blood collection, by centrifugation at 3,000 rpm for 15 minutes at room temperature. Serum aliquots were stored at $-80^{\circ} \mathrm{C}$ until further biochemical estimations.

a. Serum 25(OH)D: The ELISA technique was used for estimation of 25(OH)D using standard kits (DLD diagnostics $\mathrm{GMBH}$, intra-assay $\mathrm{CV}-5 \%$; inter-assay $\mathrm{CV}-7.8 \%)$. The vitamin D status was classified as deficient $(<50 \mathrm{nmol} / \mathrm{L})$ insufficient $(50.0-74.9 \mathrm{nmol} / \mathrm{L})$ and sufficient $(\geq 75 \mathrm{nmol} / \mathrm{L})$, based on the 2011 Endocrine Society Practice Guidelines [27]. Since primary objective of this trial was to investigate the immune modulating activity of vitamin $D$, this system was applied for vitamin D status classification as it has been devised by additionally considering the non-skeletal benefits of vitamin $D$.

b. Serum Zinc: The 2-(5-bromo-2-pyridylazo)-5-(N-propyl-Nsulfopropylamino)-phenol (5-Br-PAPS) method was used for estimating serum zinc by colorimetry (Proton Biologicals India Pvt. Ltd.; Linearity limit - up to $500 \mu \mathrm{g} / \mathrm{dL}$ ). The lower cut-offs for serum zinc are based on the guidelines suggested by IZiNCG Technical Brief [37]: < 10 years, 65 $\mu \mathrm{g} / \mathrm{dL}$; male participants $\geq 10$ years, $74 \mu \mathrm{g} / \mathrm{dL}$; female participants $\geq 10$ years, $70 \mu \mathrm{g} / \mathrm{dL}$.

\section{Infection data collection and scoring technique}

To collect information on infection-related symptoms of the participant, a validated questionnaire was administered by trained social workers to the primary caregiver [38]. Information on common infections (URTI, gastrointestinal and others, i.e. eye, skin, urinary tract infections) were collected by recording details on the duration, frequency and severity of infection-related symptoms. Data were collected every fortnight during the trial period, and data from two fortnights were collated to obtain information related to infections suffered each month. Additional 
details related to the questionnaire components, its administration, and the scoring technique have been published elsewhere [39].

System illness scores (i.e. URTI Score or Gastrointestinal Score) were computed and are expressed as percentages, based on the maximum score that could be attained. Also, a total infection score was computed as a composite of URTI, gastrointestinal, skin and urinary tract infection scores.

Depending on the scores obtained, URTI and total infection score were classified as follows: $<5$, no or mild infection; 5 to 25 , mild to moderate infection; and $>25$, severe infection [39].

\section{Statistical analysis}

Past studies have reported a difference of $8-20 \%$ in the infection rates between the supplemented group and control group [40]. Thus, to detect a difference of $16 \%$ between supplemented and control group, we estimated a sample size of $156 /$ group with $80 \%$ power and $5 \%$ level of significance.

The primary outcome measure was occurrence of infections (URTIs and total infections) in the three study arms at endline. Secondary exploratory outcomes include change in infection status according to endline serum $25(\mathrm{OH}) \mathrm{D}$ and zinc status and change in biochemical status from baseline. Statistical analysis was performed using the IBM SPSS Statistics for Windows (version 21.0.2012, Armonk, NY: IBM Corp) software. The onesample Kolmogorov-Smirnov test was used to test the normality of variables before further analysis was carried out. The results are expressed as mean \pm standard deviation (SD). ANOVA was applied to test differences between various parameters among the supplementation groups. The Kruskal-Wallis Test was used for non-normal variables. Paired Samples T-Test was used to compare the baseline to endline differences. For non-normal paired variables, the Wilcoxon Signed-Rank test was applied. Histograms were drawn to determine frequency of children within different URTI and total infection categories, at baseline and endline.

Intention-to-treat analysis was performed for all children who were randomized and completed the trial. Per-protocol analysis included all children who completed the trial without any protocol violations. Post-hoc analysis performed included association of infection status with endline vitamin D and zinc status, and change in biochemical status from baseline.

\section{RESULTS}

\section{CONSORT diagram for participant flow}

The trial CONSORT diagram is presented in Fig. 1. Within a few days of allocation and start of supplementation, 7 participants left the school as their families moved out of town. During the intervention period, 12 more participants left the school, while 5 discontinued the intervention. 45 participants were lost to follow-up during endline data collection due to absenteeism from school, and as a result, their data were not obtained. For the per-protocol analysis, 2 participants were excluded due to poor compliance to supplementation $(<50 \%)$, and 1 participant was excluded because her weight for age z-score was $<-4.0$. Thus, complete data at baseline and endline were available for 363 participants (197 boys and 166 girls): 120 in the vitamin
D arm, 119 in the zinc arm, and 124 in the placebo arm. Considering dropouts and loss to follow-up during the intervention period, the post-facto power of the trial was estimated at 0.73 .

No significant differences were observed in gender, height and weight z-scores, socio-economic status, infection scores and nutrient intakes, when comparing participants who completed the trial and those who did not. However, the ages of participants included in the final analysis were significantly lower than those who did not complete the trial $(8.0 \pm 1.2$ vs. $8.5 \pm 1.3$ years; $P<0.001$ ).

The mean compliance percentage was $88 \pm 8 \%$ with no significant difference in compliance across the three trial arms; $50 \%$ participants had $\geq 90 \%$ compliance, $46 \%$ between 70 to $89 \%$, and $4 \%$ were $<70 \%$.

The baseline characteristics of the participants are presented in Table 1.

\section{Anthropometric characteristics}

Age and anthropometric characteristics of the participants at baseline were similar for all three study arms (Table 1). Stunting (HAZ <-2.0) was noted in 10\% participants, $18 \%$ were found to be underweight (WAZ <-2.0), and 15\% exhibited thinness (i.e. $B A Z<-2.0$ ).

\section{Lifestyle}

Majority of the participants (90\%) belonged to the middle socio-economic status, while $6 \%$ belonged to low socioeconomic status and 4\% to high socio-economic status [29]. No significant differences in socio-economic status were observed between genders, supplementation groups, or trial time points (i.e. baseline and endline).

The mean environment score was $63 \%$ and personal hygiene score was $87 \%$, with no differences noted between gender, supplementation groups or trial time points [31,32].

Sunlight exposure was also similar between supplementation groups at the two trial timepoints, with most participants reporting 2 hours or more of sunlight exposure $(81 \%$ at baseline and $85 \%$ at endline). A significantly $(P<0.05)$ greater percentage of boys (36\%) reported more than 2 hours of sunlight exposure compared to girls (25\%).

\section{Nutritional intakes}

Nutritional intakes of participants at both time-points were substantially lesser than the RDA for age and sex, with intakes of micronutrient less than $50 \%$ of the RDA.

There were no dietary sources of vitamin $D$ in the foods consumed. Participants in the vitamin D group received 1,000 IU of cholecalciferol and $500 \mathrm{mg}$ of calcium. Their calcium intake (inclusive of calcium supplement) was determined to be 743 $\pm 54 \mathrm{mg}$ calcium/day during the period of supplementation (119\% of the RDA for calcium). Compared to subjects in the placebo and zinc group who were consuming an average of $230 \mathrm{mg}$ calcium per day (38\% of RDA), the calcium intake of participants in the vitamin D group was $200 \%$ higher. Their dietary calcium to phosphorus ratio thereby increased to $1.4: 1$, whereas the placebo and zinc group participants had a dietary calcium to phosphorus ratio of $0.4: 1$.

For participants in the zinc group, the total intake of zinc 
Table 1. Baseline characteristics of the participants according to study arms

\begin{tabular}{|c|c|c|c|}
\hline & Vitamin D-Calcium & Zinc & Placebo \\
\hline $\mathrm{N}$ & 120 & 119 & 124 \\
\hline \multicolumn{4}{|l|}{ Gender (\%) } \\
\hline Boys & 55 & 56 & 52 \\
\hline Girls & 45 & 44 & 48 \\
\hline Age (yrs) & $8.2 \pm 1.2$ & $7.9 \pm 1.2$ & $7.9 \pm 1.1$ \\
\hline Height (cms) & $120.7 \pm 7.4$ & $120.0 \pm 8.1$ & $119.1 \pm 6.9$ \\
\hline HAZ & $-1.0 \pm 0.8$ & $-0.8 \pm 0.9$ & $-0.9 \pm 0.8$ \\
\hline Weight (kg) & $19.8 \pm 3.5$ & $19.9 \pm 4.8$ & $19.2 \pm 3.1$ \\
\hline WAZ & $-1.3 \pm 0.7$ & $-1.2 \pm 1.0$ & $-1.3 \pm 0.8$ \\
\hline BMI $\left(\mathrm{kg} / \mathrm{m}^{2}\right)$ & $13.5 \pm 1.3$ & $13.6 \pm 1.8$ & $13.5 \pm 1.3$ \\
\hline BAZ & $-1.2 \pm 0.7$ & $-1.1 \pm 1.0$ & $-1.2 \pm 0.8$ \\
\hline \multicolumn{4}{|l|}{ Socio-economic status (\%) } \\
\hline Low & 5 & 7 & 5 \\
\hline Middle & 92 & 88 & 89 \\
\hline High & 3 & 5 & 6 \\
\hline \multicolumn{4}{|l|}{ Environment (\%) } \\
\hline Very Good & $5^{* *}$ & 11 & 11 \\
\hline Good & $46^{* *}$ & 60 & 55 \\
\hline Fair & $29^{* *}$ & 16 & 24 \\
\hline Poor & $20^{*}$ & 13 & 10 \\
\hline \multicolumn{4}{|l|}{ Personal hygiene (\%) } \\
\hline Very Good & 30 & 30 & 25 \\
\hline Good & 51 & 47 & 52 \\
\hline Fair & 14 & 17 & 18 \\
\hline Poor & 5 & 6 & 5 \\
\hline \multicolumn{4}{|l|}{ Sunlight exposure (\%) } \\
\hline$<2$ hours & 15 & 20 & 20 \\
\hline 2 to 2.5 hours & 49 & 50 & 52 \\
\hline$>2.5$ hours & 36 & 30 & 28 \\
\hline \multicolumn{4}{|l|}{ Biochemical parameters } \\
\hline Serum $25(\mathrm{OH}) \mathrm{D}(\mathrm{nmol} / \mathrm{L})$ & $60.2 \pm 11.9$ & $58.1 \pm 9.9$ & $57.7 \pm 10.0$ \\
\hline Serum Zinc $(\mu \mathrm{g} / \mathrm{dL})$ & $67.3 \pm 29.0$ & $74.7 \pm 28.3$ & $77.0 \pm 30.8$ \\
\hline \multicolumn{4}{|l|}{ Nutritional intakes } \\
\hline Calories (kcal) & $949 \pm 182(58)^{*}$ & $989 \pm 203$ & $1028 \pm 194$ \\
\hline Protein $(\mathrm{g})$ & $20 \pm 4(75)^{*}$ & $22 \pm 5(81)$ & $22 \pm 5(83)$ \\
\hline Calcium (mg) & $189 \pm 52(31)^{*}$ & $207 \pm 60$ & $218 \pm 65$ (36) \\
\hline Zinc (mg) & $3 \pm 1(35)$ & $3 \pm 1(36)$ & $3 \pm 1$ (37) \\
\hline
\end{tabular}

Values are expressed as means $\pm S D$ or percentage (\%).

HAZ, Height for age Z-score; WAZ, Weight for age Z-score; BAZ, BMl for age Z-score

* Significantly different from Placebo $(P<0.05)$

** Significantly different from Zinc $(P<0.05)$

(including zinc supplement) was $13 \pm 0.6 \mathrm{mg} /$ day during the supplementation period, enabling them to meet $160 \%$ of their RDA for zinc. The zinc intake was about $300 \%$ higher than participants in the placebo and vitamin D group, whose diets supplied $3 \pm 1 \mathrm{mg}$ zinc per day ( $36 \%$ of RDA).

\section{Biochemical parameters}

Serum 25(OH)D: The baseline mean serum 25(OH)D concentration was determined to be $58.4 \pm 10.3 \mathrm{nmol} / \mathrm{L}$, with no significant difference between genders or among the three supplementation groups. In the group receiving vitamin
D-calcium supplementation, the serum $25(\mathrm{OH}) \mathrm{D}$ concentrations significantly increased by $34 \%$ (from $59.7 \pm 10.9 \mathrm{nmol} / \mathrm{L}$ to 80 $\pm 23.3 \mathrm{nmol} / \mathrm{L})$ subsequent to 6 months of supplementation $(P<0.0001)$. Fig. 2 illustrates the change in $25(\mathrm{OH}) \mathrm{D}$ status in the three groups, from baseline to endline.

Serum Zinc: The mean serum zinc concentration at baseline was $72.3 \pm 28.2 \mu \mathrm{g} / \mathrm{dL}$, and the concentrations were similar among the three groups. Following zinc supplementation for 6 months, no significant improvement was observed in serum zinc levels in the group receiving the zinc supplement. The mean serum zinc concentration of the zinc group at endline 


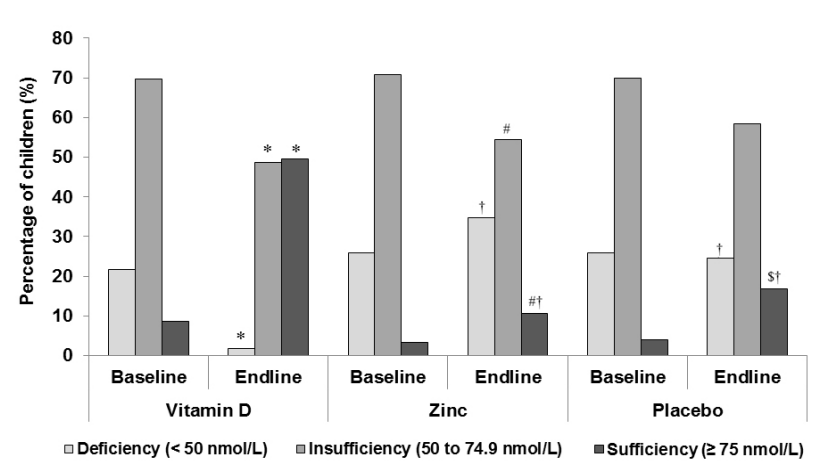

Fig. 2. Change in serum $25(\mathrm{OH}) \mathrm{D}$ status from baseline to endline. ${ }^{*}$ Significantly different from baseline vitamin D-calcium $(P<0,001)$, " Significantly different from baseline Zinc $(P<0.05),{ }^{\$}$ Significantly different from baseline Placebo $(P<0.001),{ }^{\dagger}$ Significantly different from endline vitamin D-calcium $(P<0.0001)$

was $65.2 \pm 20.4 \mu \mathrm{g} / \mathrm{dL}$, with no differences noted among the three groups. Zinc deficiency was found in $45 \%$ of the participants.

\section{Infection status}

a. Upper Respiratory Tract Infection (URTI): A positive trend in the distribution pattern of URTI was noted in each supplementation group $(P<0.0001)$. In the vitamin $D$ group, the percentage of participants having no or mild URTI (URTI score $<5$ ) increased from $38 \%$ at baseline to $65 \%$ at endline, and the percentage with high URTI scores decreased. Similarly, in the zinc arm, the percentage of participants with no or mild URTI increased from $39 \%$ at baseline to $56 \%$ at endline. In the placebo group, the percentage of participants with a URTI score of $<5$ increased from $33 \%$ to $59 \%$ after 6 months, and the percentage of participants with high URTI scores decreased compared to baseline.

b. Total Infection: Results obtained when comparing total infection scores at baseline and endline among the three supplementation groups were similar to those of URTI. After the 6 months supplementation period, the percentage of participants with no or mild total infection (TI scores $<5$ ) were significantly increased in all three groups, with a corresponding decrease of percentage participants with high TI scores. The
Table 2. Endline infection status among categories of endline serum $25(\mathrm{OH}) \mathrm{D}$

\begin{tabular}{lcc}
\hline \multicolumn{1}{c}{ Parameters } & $\begin{array}{c}\text { Vitamin D sufficiency } \\
(\geq 75 \mathrm{nmol} / \mathrm{L})(53)^{\dagger}\end{array}$ & $\begin{array}{c}\text { Vitamin D insufficiency } \\
(<75 \mathrm{nmol} / \mathrm{L})(54)^{\dagger}\end{array}$ \\
\hline Serum 25(OH)D (nmol/L) & $96.9 \pm 21.8$ & $63.4 \pm 7.6^{*}$ \\
Upper respiratory tract infections & & $0 \pm 1$ \\
Episodes & $0 \pm 1$ & $2 \pm 4$ \\
Duration (days) & $2 \pm 3$ & $9 \pm 13$ \\
URTI score & $7 \pm 11$ & \\
Total infections & & $1 \pm 1$ \\
Episodes & $0 \pm 1$ & $3 \pm 4$ \\
Duration (days) & $2 \pm 4$ & $13 \pm 16$ \\
Total infection score & $11 \pm 15$ & \\
\hline
\end{tabular}

Values are expressed as means $\pm \mathrm{SD}$.

${ }^{\dagger}$ Figures in parentheses are number of participants.

* Significantly different from Vitamin D Sufficiency $(P<0.0001)$.

percentage of participants with no or mild total infections increased from $32 \%$ to $57 \%$ in the vitamin D group, $23 \%$ to $47 \%$ in the zinc group, and $23 \%$ to $53 \%$ in the placebo group $(P<0.0001)$

While the occurrence of infections reduced significantly in all three groups, we found no significant differences when comparing reduced occurrence of URTI or total infections in the supplemented groups versus the placebo.

Infection status according to vitamin $D$ status

Since no changes were detected in serum zinc status following zinc supplementation, results of URTI and total infection status (i.e. episodes, duration and score) relating to biochemical status are presented only for the vitamin $D$ arm. At endline, the number of participants who were vitamin $D$ deficient following supplementation was only $2 \%$; hence, the participants who were deficient were pooled with those who were insufficient.

Table 2 summarizes the endline infection status with respect to the endline serum 25(OH)D levels. Although no significant differences were found in URTI and total infection status between vitamin $D$ insufficient and sufficient participants, a trend of lower URTI and total infection status was observed in the vitamin D sufficient participants.

Additionally, we evaluated URTI and total infection status in

Table 3. Infection status among categories of change in serum 25(OH)D concentrations in the vitamin $D$ arm

\begin{tabular}{|c|c|c|c|c|}
\hline \multirow{2}{*}{ Parameters $^{\dagger}$} & \multicolumn{2}{|c|}{ 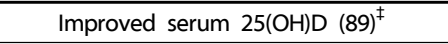 } & \multicolumn{2}{|c|}{ Unchanged serum $25(\mathrm{OH}) \mathrm{D}(18)^{\ddagger}$} \\
\hline & Baseline & Endline & Baseline & Endline \\
\hline Serum $25(\mathrm{OH}) \mathrm{D}(\mathrm{nmol} / \mathrm{L})$ & $58.0 \pm 10.4$ & $84.1 \pm 23.2^{*}$ & $66.9 \pm 11.6^{*}$ & $59.6 \pm 8.7^{* *}$ \\
\hline \multicolumn{5}{|l|}{ Upper respiratory tract infections } \\
\hline Episodes & $1 \pm 1$ & $0 \pm 1 *$ & $1 \pm 1$ & $1 \pm 1$ \\
\hline Duration (days) & $4 \pm 4$ & $2 \pm 3^{*}$ & $4 \pm 5$ & $3 \pm 5$ \\
\hline URTI score & $14.5 \pm 13.8$ & $7.9 \pm 11.7^{*}$ & $13.7 \pm 13.5$ & $10.4 \pm 13.4$ \\
\hline \multicolumn{5}{|l|}{ Total infections } \\
\hline Episodes & $1 \pm 1$ & $0 \pm 1 *$ & $1 \pm 1$ & $1 \pm 1$ \\
\hline Duration (days) & $5 \pm 5$ & $3 \pm 4^{*}$ & $5 \pm 6$ & $4 \pm 5$ \\
\hline Total infection score & $19.2 \pm 16.3$ & $11.4 \pm 14.8^{*}$ & $19.3 \pm 17.0$ & $15.9 \pm 18.3$ \\
\hline
\end{tabular}

Values are expressed as means $\pm \mathrm{SD}$

${ }^{\dagger}$ All parameters were non-normal and non-parametric tests have been used to test differences between groups.

${ }^{\ddagger}$ Figures in parentheses are number of participants.

* Significantly different from baseline of improved serum $25(\mathrm{OH}) \mathrm{D}(P<0.0001)$

** Significantly different from endline of improved serum $25(\mathrm{OH}) \mathrm{D}(P<0.0001)$ and from baseline of unchanged serum $25(\mathrm{OH}) \mathrm{D}(P<0.0001)$. 
participants categorized according to their change in serum 25(OH)D concentrations, i.e., improvement versus relatively unchanged serum 25(OH)D levels, following vitamin D-calcium supplementation (Table 3). No significant differences were observed in the infection status at baseline or endline between the improved $25(\mathrm{OH}) \mathrm{D}$ group versus the unchanged $25(\mathrm{OH}) \mathrm{D}$ group.

We further determined that in the group with improved 25(OH)D levels, URTI and total infection status (viz., the number of episodes, duration of infection and infection score) was significantly reduced when compared to baseline $(P<0.0001)$. However, no statistical significance was observed for the change in infection status in the $25(\mathrm{OH}) \mathrm{D}$ unchanged group (Table 3 ).

\section{Intention to treat analysis}

The intention to treat analysis were similar to results obtained in the per-protocol analysis. When compared as a whole with the placebo group, improvement in vitamin $D$ group infection status was at par with the placebo group. Similar results were obtained when considering the vitamin D status; improved vitamin $D$ concentrations in the vitamin $D$ group demonstrated improved infection status.

\section{DISCUSSION}

Our trial population of 6-12-year-old children from a rural setting comprised a majority who received more than 2 hours of sunlight exposure, had a mean serum $25(\mathrm{OH}) \mathrm{D}$ concentration of $58.4 \pm 10.3 \mathrm{nmol} / \mathrm{L}$, and $45 \%$ revealed zinc deficiency. No significant reduction was observed in the occurrence of infections, in either the vitamin D group or the zinc group when compared to the placebo group. However, we observed a trend of lower URTI and total infections in participants who were vitamin D sufficient as compared to vitamin D insufficient participants. We further observed significant improvement in the URTI and total infection status in participants with improved serum 25(OH)D concentrations as compared to participants with unchanged levels. Majority of the trial participants belonged to the middle socio-economic strata, with similar living conditions and personal hygiene habits.

To our knowledge, this is the first intervention trial in a rural population of 6-12-year-old children, undertaken to determine the effect of supplementation with either vitamin D or zinc, on the occurrence of common infections.

The anthropometric characteristics of all participants across the three trial arms at baseline were similar. Prevalence of stunting $(10 \%)$ and underweight (18\%) were comparable to those reported in rural schoolchildren aged 5-14 years from Bengaluru (17\% stunting and 17\% underweight) [41].

In all three groups, we observed a significant increase in the percentage of children with no to mild URTI as well as no to mild total infections, as compared to the baseline, with consequent reduction in the percentage of children with severe infections. Overall, no improvements were observed when comparing the supplementation groups with placebo group.

Our study revealed significant improvement in the vitamin D status of participants, following daily supplementation for 6 months with $1,000 \mathrm{IU}$ vitamin D and $500 \mathrm{mg}$ calcium. The percentage of participants in the vitamin D group with sufficient
$25(\mathrm{OH}) \mathrm{D}$ concentrations rose from $9 \%$ at baseline to $50 \%$ at endline (Fig. 2). The efficacy of this dose of vitamin D supplementation has been documented by us in an earlier publication [42].

Next, we assessed the infection status at endline by considering the different categories of endline serum 25(OH)D status of participants in the vitamin $D$ arm. No statistical differences were observed between participants when comparing the 25(OH)D status. However, a trend of lower infection status was observed among participants who were vitamin D sufficient. Additionally, assessment for alterations in the infection status within categories of changed vitamin $D$ concentrations revealed that improved vitamin $\mathrm{D}$ concentrations resulted in significant improvement in the infection status.

Vitamin D supplementation to reduce infections in children has yielded varied results. Martineau et al. [43], in their metaanalysis to test the effect of vitamin $D$ on the incidence of acute respiratory tract infections, reported that while vitamin $D$ exerted a protective effect against respiratory infections, the benefits were largely experienced by participants who were severely vitamin $D$ deficient. They report that participants with baseline serum $25(\mathrm{OH}) \mathrm{D}$ concentration $<25 \mathrm{nmol} / \mathrm{L}$ who received frequent low doses of vitamin $D$ supplements showed the maximum beneficial effect against respiratory tract infections.

In the current trial, while we administered frequent, low dose vitamin $D$ supplements which produced a statistically significant improvement in the vitamin D status, none of the trial participants were severely vitamin $D$ deficient. At baseline, only $20 \%$ participants in the vitamin D arm were deficient (serum $25 \mathrm{OHD}<50 \mathrm{nmol} / \mathrm{L}$ ), with minimum serum 25(OH)D concentration being $40 \mathrm{nmol} / \mathrm{L}$. Based on previous finding of prevalence of up to $75 \%$ deficiency among children in rural South India in spite of them having around 8 hours of sunlight exposure [7], we had expected a majority in this population to be vitamin D deficient. However, most of the participants (70\%) in the current trial had insufficient vitamin D, and only about $20 \%$ were deficient. We therefore speculate that since the participants in our study were not severely vitamin D deficient, the reduction in occurrence of URTI or total infections in participants in the vitamin D group as compared to placebo group was not significant. However, we observed a trend of lower infection status in vitamin D sufficient participants and significantly improved infection status in participants with improved $25(\mathrm{OH}) \mathrm{D}$ levels.

In the zinc arm of the trial, we found that zinc supplementation exerted no benefit in improving the zinc status of the participants. No significant differences in serum zinc concentrations were observed among participants who received zinc supplement and those who did not. The following factors may be responsible for inability of the supplement to improve zinc status. 1) Insufficient or inadequate amount of supplemental zinc administered: While reports suggest that supplementation with up to $10 \mathrm{mg}$ of zinc may be considered for preventive supplementation in children under 14 years of age, there are as yet no guidelines available for preventive zinc supplementation [44]. Hence, we administered a supplement that would meet at least 1 RDA of zinc ( 7 to $9 \mathrm{mg} /$ day) for the trial participants. Other researchers have used higher zinc doses for younger children (10 mg to $70 \mathrm{mg}$ zinc daily for children aged 
22 to 66 months) [45]. 2) Reduced bioavailability of zinc from the supplement due to other components in the supplement which may have interfered with zinc absorption [25]. While conflicting results of the effect of zinc supplementation on incidence of childhood infections like common colds, diarrhea, etc. have been reported, authors have recognized the benefits of zinc supplementation for zinc deficient populations $[25,44]$. Thus, further investigations into the effect of zinc supplementation on immune response in children are warranted.

This trial has some limitations. One limitation was that the recording of infection-related data was performed using a questionnaire, and we did not have any additional objective assessment of infections suffered by the participant. However, infection data was recorded regularly (every fortnight) to avoid recall bias. Additionally, we recorded the numbers of days and reason for absence from school, details of treatment taken, home remedies administered, and details of medical reports, if any. This helped in validating the data collected by the questionnaire, thereby resulting in accurate recording of infections suffered by the participants. Considering that the effect of vitamin $D$ supplementation on the immune response is more likely observed in participants who are severely vitamin D deficient (i.e., serum vitamin $D<25 \mathrm{nmol} / \mathrm{L}$ ), an important limitation of this trial was that none of the participants were severely deficient. This may be one of the reasons that we were unable to detect a decrease in occurrence or duration of infections greater than that observed in the placebo group.

Thus, in 6-12-year-old children having poor nutritional intake, adequate sunlight exposure, and insufficient vitamin D status, supplementation with $1,000 \mathrm{IU}$ vitamin D and $500 \mathrm{mg}$ calcium helps in improving the vitamin $D$ status but had no effect on the occurrence of childhood infections. Improvement in vitamin D concentrations and attainment of vitamin D sufficiency could exert beneficial effects on the infection status and needs to be investigated further. For success of zinc supplementation among these children, higher dosages of zinc supplement need to be administered in future studies.

\section{CONFLICT OF INTEREST}

The authors declare no potential conflicts of interest.

\section{ACKNOWLEDGMENTS}

Rubina Mandlik was funded by a Fellowship Grant from the University Grants Commission, Government of India. We are thankful to Eris Lifesciences Ltd. Ahmedabad who kindly supplied the vitamin D supplements. We are grateful for the help and support of the social workers who administered the supplements to the children and maintained meticulous records of the administrations. We wish to express our sincere gratitude to all the children and parents who participated in this study. We also wish to thank the school principals, teachers and school staff.

\section{ORCID}

Rubina Mandlik: https://orcid.org/0000-0002-4660-3013

Zulf Mughal: https://orcid.org/0000-0002-8603-5663
Anuradha Khadilkar: https://orcid.org/0000-0002-3399-3235

Shashi Chiplonkar: https://orcid.org/0000-0001-5636-1946

Veena Ekbote: https://orcid.org/0000-0001-9226-8167

Neha Kajale: https://orcid.org/0000-0001-5129-481X

Vivek Patwardhan: https://orcid.org/0000-0002-7985-9808

Raja Padidela: https://orcid.org/0000-0002-3350-9896

Vaman Khadilkar: https://orcid.org/0000-0001-7719-1341

\section{REFERENCES}

1. International Institute for Population Sciences. National Family Health Survey (NFHS-4): 2015-16. Mumbai: International Institute for Population Sciences; 2017.

2. Scrimshaw NS. Effect of infection on nutritional status. Proc Natl Sci Counc Repub China B 1992;16:46-64.

3. Maggini S, Wintergerst ES, Beveridge S, Hornig DH. Selected vitamins and trace elements support immune function by strengthening epithelial barriers and cellular and humoral immune responses. Br J Nutr 2007;98 Suppl 1:S29-35.

4. Suaini $\mathrm{NH}$, Zhang $\mathrm{Y}$, Vuillermin PJ, Allen $\mathrm{KJ}$, Harrison LC. Immune modulation by vitamin $D$ and its relevance to food allergy. Nutrients 2015;7:6088-108.

5. Wacker M, Holick MF. Vitamin D - effects on skeletal and extraskeletal health and the need for supplementation. Nutrients 2013;5:111-48.

6. Londhey V. Vitamin D deficiency: Indian scenario. J Assoc Physicians India 2011;59:695-6.

7. Harinarayan CV, Ramalakshmi T, Prasad UV, Sudhakar D. Vitamin D status in Andhra Pradesh: a population-based study. Indian J Med Res 2008;127:211-8.

8. Harinarayan C, Holick M, Prasad U V, Vani PS, Himabindu G. Vitamin D status and sun exposure in India. Dermatoendocrinol. 2013;5(1): 130-41.

9. Clements MR, Johnson L, Fraser DR. A new mechanism for induced vitamin D deficiency in calcium deprivation. Nature 1987;325:62-5.

10. Pettifor JM. Nutritional rickets: deficiency of vitamin D, calcium, or both? Am J Clin Nutr 2004;80:1725S-1729S.

11. Khadilkar A, Kadam N, Chiplonkar S, Fischer PR, Khadilkar V. Schoolbased calcium-vitamin $\mathrm{D}$ with micronutrient supplementation enhances bone mass in underprivileged Indian premenarchal girls. Bone 2012;51:1-7.

12. Lappe JM, Heaney RP. Why randomized controlled trials of calcium and vitamin D sometimes fail. Dermatoendocrinol 2012;4:95-100.

13. Kapil U, Jain K. Magnitude of zinc deficiency amongst under five children in India. Indian J Pediatr 2011;78:1069-72.

14. Tupe RP, Chiplonkar SA. Zinc supplementation improved cognitive performance and taste acuity in Indian adolescent girls. J Am Coll Nutr 2009;28:388-96.

15. Sivakumar B, Vijayaraghavan K, Vazir S, Balakrishna N, Shatrugna V, Sarma KV, Nair KM, Raghuramulu N, Krishnaswamy K. Effect of micronutrient supplement on health and nutritional status of schoolchildren: study design. Nutrition 2006;22 Suppl:S1-7.

16. Thomas $T$, Eilander A, Muthayya $S$, McKay $S$, Thankachan $P$, Theis W, Gandhe A, Osendarp SJ, Kurpad AV. The effect of a 1-year multiple micronutrient or n-3 fatty acid fortified food intervention on morbidity in Indian school children. Eur J Clin Nutr 2012; 66:452-8.

17. Ananthakrishnan S, Pani SP, Nalini P. A comprehensive study of morbidity in school age children. Indian Pediatr 2001;38:1009-17. 
18. Chowdhury SD, Ghosh T. Nutritional and socioeconomic status in cognitive development of Santal children of Purulia district, India. Ann Hum Biol 2011;38:188-93.

19. Manaseki-Holland S, Maroof Z, Bruce J, Mughal MZ, Masher MI, Bhutta ZA, Walraven G, Chandramohan D. Effect on the incidence of pneumonia of vitamin $D$ supplementation by quarterly bolus dose to infants in Kabul: a randomised controlled superiority trial. Lancet 2012;379:1419-27.

20. Aluisio AR, Maroof $Z$, Chandramohan D, Bruce J, Mughal MZ, Bhutta Z, Walraven G, Masher Ml, Ensink JH, Manaseki-Holland S. Vitamin D3 supplementation and childhood diarrhea: a randomized controlled trial. Pediatrics 2013;132:e832-40.

21. Urashima $M$, Segawa $T$, Okazaki $M$, Kurihara $M$, Wada $Y$, Ida $H$. Randomized trial of vitamin $D$ supplementation to prevent seasonal influenza A in schoolchildren. Am J Clin Nutr 2010;91:1255-60.

22. Lang PO, Aspinall R. Can we translate vitamin D immunomodulating effect on innate and adaptive immunity to vaccine response? Nutrients 2015;7:2044-60.

23. Kurugöl Z, Bayram N, Atik T. Effect of zinc sulfate on common cold in children: randomized, double blind study. Pediatr Int 2007;49: 842-7.

24. Müller $O$, Becher $H$, van Zweeden $A B$, Ye $Y$, Diallo $D A$, Konate $A T$, Gbangou A, Kouyate B, Garenne M. Effect of zinc supplementation on malaria and other causes of morbidity in west African children: randomised double blind placebo controlled trial. BMJ 2001; 322:1567.

25. Somé JW, Abbeddou S, Yakes Jimenez E, Hess SY, Ouédraogo ZP Guissou RM, Vosti SA, Ouédraogo JB, Brown KH. Effect of zinc added to a daily small-quantity lipid-based nutrient supplement on diarrhoea, malaria, fever and respiratory infections in young children in rural Burkina Faso: a cluster-randomised trial. BMJ Open 2015;5:e007828.

26. Solar Energy Centre, MNRE; Indian Metrological Department. Typical Climatic Data for Selected Radiation Stations (The Data Period Covered: 1986-2000). Solar Radiation Hand Book (2008) [Internet]. New Delhi: Indian Metrological Department; 2008 [cited 2017 Oct 28]. Available from: http://www.indiaenvironmentportal.org.in/files/ srd-sec.pdf.

27. Holick MF, Binkley NC, Bischoff-Ferrari HA, Gordon CM, Hanley DA, Heaney RP, Murad MH, Weaver CM; Endocrine Society. Evaluation, treatment, and prevention of vitamin $\mathrm{D}$ deficiency: an Endocrine Society clinical practice guideline. J Clin Endocrinol Metab 2011;96: 1911-30.

28. Indian Council of Medical Research. Nutrient Requirements \& Recommended Dietary Allowances for Indians. Hyderabad: Expert Group of the Indian Council of Medical Research; 2009.

29. Kumar N, Shekhar C, Kumar P, Kundu AS. Kuppuswamy's socioeconomic status scale-updating for 2007. Indian J Pediatr 2007.74: 1131-2.

30. Patwardhan VG, Khadilkar AV, Chiplonkar SA, Mughal ZM, Khadilkar W. Varying relationship between 25-hydroxy-vitamin D, high density lipoprotein cholesterol, and serum 7-dehydrocholesterol reductase with sunlight exposure. J Clin Lipidol 2015;9:652-7.

31. Deb S, Dutta S, Dasgupta A, Misra R. Relationship of personal hygiene with nutrition and morbidity profile: a study among primary school children in South Kolkata. Indian J Community Med 2010;35:280-4.
32. Chiplonkar SA, Agte W, Mengale SS, Tarwadi KV. Are lifestyle factors good predictors of retinol and vitamin C deficiency in apparently healthy adults? Eur J Clin Nutr 2002;56:96-104.

33. Khadilkar V, Yadav S, Agrawal KK, Tamboli S, Banerjee M, Cherian A, Goyal JP, Khadilkar A, Kumaravel V, Mohan V, Narayanappa D, Ray I, Yewale V; Indian Academy of Pediatrics Growth Charts Committee. Revised IAP growth charts for height, weight and body mass index for 5- to 18-year-old Indian children. Indian Pediatr 2015;52:47-55.

34. Chiplonkar S. CDiet - BELLYCHEATERS [Internet]. Pune: BELLYCHEATERS; [cited 2018 Oct 5]. Available from: https://bellycheaters.com/cdiet/.

35. Longvah T, Ananthan R, Bhaskarachary K, Venkaiah K; National Institute of Nutrition. Indian Food Composition Tables. 1st ed. Longvah T, editor. Hyderabad: National Institute of Nutrition; 2017.

36. Chiplonkar SA, Agte W. Extent of error in estimating nutrient intakes from food tables versus laboratory estimates of cooked foods. Asia Pac J Clin Nutr 2007;16:227-39.

37. Brown KH. IZiNCG Technical Brief: Assessing Population Zinc Status with Serum Zinc Concentration. Davis (CA): International Zinc Nutrition Consultative Group; 2012.

38. Bruijnzeels MA, Foets $M$, van der Wouden JC, Prins A, van den Heuvel WJ. Measuring morbidity of children in the community: a comparison of interview and diary data. Int J Epidemiol 1998;27: 96-100.

39. Mandlik R, Chiplonkar S, Kajale N, Khadilkar V, Khadilkar A. Infection status of rural schoolchildren and its relationship with Vitamin $D$ concentrations. Indian J Pediatr 2019;86:675-80.

40. Camargo CA Jr, Ganmaa D, Frazier AL, Kirchberg FF, Stuart J, Kleinman K, Sumberzul N, Rich-Edwards JW. Randomized trial of vitamin $\mathrm{D}$ supplementation and risk of acute respiratory infection in Mongolia. Pediatrics 2012;130:e561-7.

41. Shalini CN, Murthy NS, Shalini S, Dinesh R, Shivaraj NS, Suryanarayana SP. Comparison of nutritional status of rural and urban school students receiving midday meals in schools of Bengaluru, India: a cross sectional study. J Postgrad Med 2014;60:118-22.

42. Mandlik R, Khadilkar A, Kajale N, Ekbote V, Patwardhan V, Mistry S, Khadilkar V, Chiplonkar S. Response of serum 25(OH)D to Vitamin $\mathrm{D}$ and calcium supplementation in school-children from a semi-rural setting in India. J Steroid Biochem Mol Biol 2018;180:35-40.

43. Martineau AR, Jolliffe DA, Hooper RL, Greenberg L, Aloia JF, Bergman P, Dubnov-Raz G, Esposito S, Ganmaa D, Ginde AA, Goodall EC, Grant CC, Griffiths CJ, Janssens W, Laaksi I, Manaseki-Holland S, Mauger D, Murdoch DR, Neale R, Rees JR, Simpson S Jr, Stelmach I, Kumar GT, Urashima M, Camargo CA Jr. Vitamin D supplementation to prevent acute respiratory tract infections: systematic review and meta-analysis of individual participant data. BMJ 2017;356:16583.

44. Mayo-Wilson E, Junior JA, Imdad A, Dean S, Chan XH, Chan ES, Jaswal A, Bhutta ZA. Zinc supplementation for preventing mortality, morbidity, and growth failure in children aged 6 months to 12 years of age. Cochrane Database Syst Rev 2014:CD009384.

45. Moran VH, Stammers AL, Medina MW, Patel S, Dykes F, Souverein OW, Dullemeijer C, Pérez-Rodrigo C, Serra-Majem L, Nissensohn M, Lowe NM. The relationship between zinc intake and serum/plasma zinc concentration in children: a systematic review and dose-response meta-analysis. Nutrients 2012;4:841-58. 